\title{
Três observações sobre a sociologia da infâncial*
}

\author{
Marcel Mauss
}

\section{Apresentação de Marcel Fournier}

"Três observaçôes sobre a sociologia da infância" é o texto da conferência que Marcel Mauss deveria apresentar em julho de 1937 em um Congresso de Sociologia da Infância. Devido a seu estado de saúde e a suas numerosas obrigaçôes, ele não pôde estar presente e enviou seu texto - datilografado em sete páginas ${ }^{2}$-, desculpando-se por sua "relativa incompetência": "Eu sei pouco sobre a sociologia da infância [...] mas nós não podemos tudo saber nem tudo fazer, e esse é um ensaio de um intelectual próximo que eu submeto a vossa aprovação $0^{3 .}$.

Evidentemente, essa não foi a primeira vez que Mauss abordou o problema da educação e da relação entre as gerações. A educação era uma preocupação central para Durkheim e seus colaboradores: na realidade, é na educação que a ação da

1. Tradução: Renato Abramowicz Santos. Revisão Técnica: Anete Abramowicz

Este texto, que se apresenta em um manuscrito inacabado escrito pelo sociólogo e antropólogo francês, Marcel Mauss, sobrinho de Émile Durkheim, é pela primeira vez traduzido para o português, e é considerado um dos textos inaugurais da sociologia da infância francesa. O texto foi recuperado pelo professor Marcel Fournier, da Universidade de Montreal, e publicado pela Revista de Antropologia denominada Gradhiva, em 1996. Marcel Mauss apresentaria tal texto como comunicação em um Congresso da sociologia da infância em 1937. As questões postas por Mauss neste texto são ainda objeto de análise e debate no interior do campo da sociologia da infância. A infância como um meio social para a criança, o problema das gerações, as técnicas do corpo e a educação da infância fazem parte do repertório teórico da sociologia da infância, que vem cada vez mais se constituindo como um campo profícuo e fecundo de pesquisas tanto para a sociologia quanto para a educação. Ao compor uma genealogia do campo da sociologia da infância, este texto é, sem dúvida, imprescindível.

* N. E. A editoria da Pro-Posições agradece especialmente à Profa. Dra. Anete Abramowicz, responsável pela indicação e encaminhamento deste texto aos editores da revista. Além do apoio necessário para a obtenção dos direitos para publicação, muito colaborou no preparo da apresentação e na revisão técnica do texto traduzido.

2. Esse texto faz parte do fundo Hubert-Mauss conservado nos arquivos do Collège de France. Cf. Marcel Fournier, Marcel Mauss, Paris, Fayard, 1994.

3. Carta de Marcel Mauss a "Monsieur le Président", 6 de julho de 1937 (Fundo Hubert-Mauss, arquivos do Collège de France). 
sociedade sobre o individuo se observa melhor ${ }^{4}$. Quem diz educação diz formação de uma geração por outra, ou melhor, adestramento da criança pelo adulto.

Toda uma parte do "Fragmento de um plano de sociologia geral descritiva", que Mauss publicou nos Anais sociológicos, em 1934, é consagrada à educação; trata-se também de questão de disciplina, de autoridade, de tradição.

\begin{abstract}
Podemos [ele escreve] chamar de educação (ou instrução) os esforços conscientemente feitos pelas geraçōes para transmitir suas tradiçôes a uma outra. Podemos também dar esse nome, menos abstratamente, à ação que os antigos exercem sobre as geraçōes que chegam a cada ano para moldá-las em relação a eles mesmos e, em segundo lugar, para adaptá-las a seus meios social e físico 5 .
\end{abstract}

E tudo isso não se dá, ele destaca, sem violência: "A educação consiste igualmente em uma série de provações, algumas trágicas: circuncisão, etc., humilhações constantes $^{6 "}$.

O interesse que Mauss demonstrava, em 1937, pela sociologia da infância talvez não seja totalmente independente da presença, no Collège de France, de Henri Wallon (1879-1962). Titular da cadeira de Psicologia e de Educação da Infância (criada em 1935), Wallon é o autor de uma obra sobre As Origens do caráter na criança. Os prelúdios do sentimento de personalidade (1934). Aliás, um amigo de Mauss, Ignace Meyerson (1888-1983), trabalhou no início de 1920 com Signe graphique chez l'enfant ${ }^{7}$ e redigiu um apêndice para a obra de Jean Piaget, La représentation du monde chez l'enfant ${ }^{8}$.

Marcel Mauss e Jean Piaget conheciam-se. Ambos participaram, em abril de 1928, do primeiro encontro franco-alemão de Davos: um falou dos "Métodos novos da etnografia" e o outro de "A lógica da criança". Em 1931, eles se encontraram novamente durante a Terceira Semana Internacional de Sintese organizada pelo Centro Internacional de Sintese. Jean Piaget e Pierre Janet apresentaram uma conferência sobre "A individualidade", após a qual interveio Marcel Mauss.

A discussão foi acalorada: Mauss expôs claramente seus pontos de divergência em relação a seu colega suiço. Primeiramente, ele o criticou por "ter feito, não psicologia

4. Cf. FAUCONNET, Paul; MAUSS, Marcel. Sociologie, La Grande Encyclopédie, t. 30, I 90 I. In: MAUSS, Marcel. Euvres 3. Paris: Éditions de Minuit, 1969. p. 139- 177 (edição de Victor Karady).

5. Cf. MAUSS, Marcel. Fragments d'un plan de sociologie générale descriptive. Classification et méthode d'observation des phénomènes généraux de la vie sociale dans les sociétés de types archaïques (phénomènes généraux spécifiques à la vie intérieure de la société), Annales sociologiques, série A, fascículo I, 1934. In: MAUSS, Marcel. Furres 3. Paris: Éditions de Minuit, 1969. p. 340 (edição de Victor Karady).

6. Ibid., p. 343.

7. Signo gráfico na criança (N.T.).

8. A representação do mundo na criança (N.T.).

Pro-Posições, Campinas, v. 21, n. 3 (63), p. 237-244, set./dez. 2010 
da criança em geral, mas psicologia da criança mais civilizada" e aconselhou-o a "fazer observaçôes rigorosas e extensas, por exemplo, na África do Norte, antes de tirar qualquer conclusão mais geral".

A criança marroquina [precisa Mauss] é habilidosa e trabalha bem mais cedo do que nossas crianças. Sobre certos pontos, portanto, ela raciocina antes e mais rápido e de outro modo - manualmente do que as crianças de nossas boas familias burguesas.

A segunda divergência foi de ordem metodológica:

Os durkheimianos em geral, e eu inclusive, desenvolvemos nossas pesquisas sobre elementos da razão tomados separadamente, categoria por categoria. O senhor Piaget crê poder abraçar o sistema inteiro da experiência em geral; épor isso que nossos resultados são necessariamente diferentes ${ }^{I 0}$.

Enfim, uma terceira e última reserva, "do ponto de vista moral": "A distância entre os 'primitivos' e nós é menor do que crê o senhor Piaget. Ele faz da noção de reciprocidade um privilégio do indivíduo saido da infância, ou da sociedade já civilizada"1. E, em resposta a Piaget, Mauss concluiu: "Em suma, o senhor parte do individual, e nós do social, mas é o mesmo objeto que observamos pelos lados opostos do binóculos" ${ }^{\prime 2}$. A perspectiva do sociólogo é, ao mesmo tempo, relativista e evolucionista: "O pensamento humano passou de uma representação simbólica e empirica para a demonstração, para a geometria e para uma experiência que se apoia na razão" 13 .

Marcel Mauss abordou novamente a questão da educação durante o Congresso Internacional de Ciências Antropológicas e Etnológicas que ocorreu em Copenhague no verão de 1936.

9. Cf. MAUSS, Marcel. Intervenção posterior à conferência de P. Janet e de J. Piaget: "L'individualité", Centro internacional de síntese, Terceira Semana Internacional de Síntese (1931), Paris, Alcan, 1934. In: MAUSS, Marcel. Euvres 3. Paris: Éditions de Minuit, 1969. p. 300 (edição de Victor Karady).

Na conferência que ele apresentou no mesmo ano no Instituto Francês de Sociologia, Mauss fez referência à discussão que ele teve "outro dia" com um "psicólogo eminente" sobre a formação da razão, e retomou o mesmo argumento [MAUSS, Marcel. La cohésion sociale dans les sociétés polysegmentaires (1931). In: MAUSS, Marcel. Euvres 3. Paris: Éditions de Minuit, 1969. p. 23 (edição de Victor Karady).

10. Ibid.

I1. Ibid., p. 301.

12. Ibid.

13. Ibid., p. 302.

Pro-Posições, Campinas, v. 21, n. 3 (63), p. 237-244, set./dez. 2010 
O homem é, afirma Mauss, um animal que educa e adestra suas crianças [...]. Enem estou falando sobre as torturas do martelo que foram infligidas a minha geração, eu falo do arcabouço de cuidados que permite, por exemplo, adestrar e educar a criança muito cedo.

É suficiente, para convencer-se, tomar alguns exemplos concretos tirados da vida cotidiana de nossas sociedades: as horas de refeição, a maneira de responder aos choros da criança e de pegá-las nos braços. Sobre esse ponto também, Mauss faz referência às sociedades ditas primitivas e a seus ritos de iniciação. O título de sua conferência é "Fato social e formação do caráter"l4.

14. MAUSS, Marcel. "Fait social et formation du caractère". Congresso Internacional de Ciências Antropológicas e Etnológicas. Copenhague, 1936. (Fundo Hubert-Mauss, Arquivos do Collège de France). Trata-se de um texto manuscrito, com nove páginas, difícil de decifrar e manifestamente incompleto. A última página comporta certo número de notas estenográficas: técnicas do corpo, esporte, cavalo, etc. São temas que Mauss aborda também em seu texto "Les techniques du corps" (Journal de Psychologie Normale et Pathologique, 1935, n. 32, p. 27I-293. In: MAUSS, Marcel. Sociologie et anthropologie. Paris: PUF, 1950. p. 362-386).

Pro-Posições, Campinas, v. 21, n. 3 (63), p. 237-244, set./dez. 2010 


\section{Três observações sobre a sociologia da infância}

Marcel Mauss

Senhores, eu sinto poder apenas submeter a vossa aprovação ou a vossa desaprovação as indicaçôes que eu vou lhes apresentar e não desenvolvê-las de maneira mais extensa na vossa frente; e tampouco defendê-las, se necessário. Aliás, elas são mais indicaçōes de temas de trabalho do que indicações de resultados.

Elas se referem a três pontos bem distintos uns dos outros que, no entanto, possuem conexões que não tentarei demonstrar aqui. Todo problema sociológico - mesmo aqueles que dizem respeito à criança - tem múltiplas relaçóes com todos os outros problemas sociológicos ou mesmo antropológicos, isto é, biológicos e psicológicos, pois, na vida social, sublimação da vida propriamente dita, existe, necessariamente, unidade e organismo.

Contudo, eu apresento essas observaçôes desvinculadas umas das outras, exceto pelo espírito que as anima.

\section{A infância, meio social para a criança}

Uma parte da psicologia da criança, por exemplo, aquela que concebe e pratica o eminente psicólogo e pedagogo que é o Senhor Professor Piaget ${ }^{1}$, de Genebra, consiste, na realidade, na análise muito aprofundada da mentalidade de um pequeno grupo de crianças, em particular das suas.

Desde já a interrogação sendo empurrada assim tão longe como ela é por ele, faz aparecer rapidamente o substrato social, pois ela é o estudo de crianças determinadas de um meio determinado, de crianças de língua francesa educadas de certo modo historicamente determinado.

Consequentemente, todo estudo de psicologia da criança, ao tratar e analisar suas ideias a partir do interrogatório do psicólogo, é, em algum grau, um estudo sociológico, mas a ele é preciso adicionar um estudo mais especificamente sociológico dos meios infantis, enquanto meios, propriamente.

O interesse dessas questões é fundamental, por um lado, do ponto de vista da sociologia moral, em particular, e mesmo jurídica; e, por outro, do ponto de vista do estudo da formação de um meio qualquer.

I. Em 1931, Mauss havia já debatido as pesquisas de Piaget, na presença deste (cf. supra, nota 6). 
Aliás, esse estudo começado, se estou presumindo bem, é, em parte, o objeto de vossos trabalhos.

Mas eu gostaria de indicar, a este respeito, duas questôes que já foram postas e tratadas suficientemente na América.

Elas são os estudos psicossociológicos e as estatísticas psicossociológicas de caso, daquilo que Chapin chama de a formação do leader. Em um meio de crianças, um jogo, por exemplo, não só o próprio jogo tem, por si só, frequentemente, o objetivo de determinar quem é o líder, o chefe, o campeão, a criança forte, a criança esperta, o bom dançarino, o bom corredor, etc., mas as crianças, brincando juntas, formam um meio que tem sua moral, suas regras de jogo, sua força.

Já faz bastante tempo que, como Gummere (The beginnings of poetry) ${ }^{2}$, nós aproximamos, da roda de crianças e do protagonista sobre a qual ela se fecha, as formas rituais e poéticas e artísticas e musicais consideráveis e, como se diz com bastante imprecisão, primitivas.

Não só Chapin, mas também toda uma multidão de psicólogos e de fisiólogos americanos continuaram esses estudos. Permito-me recomendar o trabalho de um jovem intelectual, Senhor Eugène Lerner, intitulado: Constraint areas and the moral judgement of children (Áreas de restrição e julgamentos morais das crianças).

Pela análise das pesquisas psicossociológicas, os julgamentos de valor moral de 389 crianças de 6 a 12 anos, da cidade de Montclair, uma das mais reputadas por suas escolas e pela excelência de sua educação do Estado de New Jersey (região de New York), vemos como se desprende a concepção que a criança tem, de um lado, do papel de seus pais da concepção que ela, por outro lado, tem do papel de sua moral (naquilo que concerne à mentira, ao erro, à punição imanente, etc.) — não só uma moral geral, mas também uma moral verdadeira, segundo os meios aos quais a criança pertence, mesmo depois do nivelamento da escola onde essas crianças foram interrogadas, que já constitui (por si só) um meio".

Toda essa noção do meio infantil está na base do famoso livro de W. I. Thomas: Education in America.

Todos esses estudos podem e devem ser feitos e podem e devem culminar bem rapidamente em resultados relativamente confiáveis, pois, enfim, por exemplo, 389 crianças, em uma mesma escola, oriundas de diferentes meios representam grandes números, quando estudamos a seu respeito uma variedade de

2. Cf. F. B. Gummere. The beginnings of poetry, New York, I 90 I. Em L'Année Sociologique, 1903, n. 6. Mauss redigiu uma resenha da obra de Gummere sob o título: "Les débuts de la poésie selon Gummere", incluído em MAUSS, Marcel. Euvres 2. Paris: Éditions de Minuit, 1969. p. 25I-255 (edição de Victor Karady). 
fenômenos. A tabulação estatística desses fenômenos é importante para o estudo do meio infantil e também para o estudo do meio social em geral, que formarão, um dia, essas crianças.

\section{Problemas de gerações}

É aqui, pois, que se coloca o problema fundamental não só da educação, mas também de toda sociologia possível.

Linguistas, teóricos do direito, teóricos da história da arte, todos, mesmo simples críticos, têm a percepção aguda de um fenômeno fundamental do qual nós ainda não nos damos bem conta, e que é preciso estudar rapidamente: o das geraçōes.

Por razões desconhecidas, que não saberíamos descrever com precisão, acontece que a própria fonética de uma linguagem, e muito mais a semântica de suas palavras, até mesmo o próprio vocabulário e, muito mais ainda, suas palavras em particular, por exemplo, na gíria ${ }^{3}$ - mudam de uma geração para outra.

Em um meio de crianças, surgem constantemente novas formas de linguagem, que se perdem, que se difundem em maior ou menor grau. Eu até me lembro, enquanto criança, de ter inventado uma punição para nosso pequeno círculo de primos e de amigos, que eu havia nomeado de potte-au-feu ${ }^{4}$, à qual os mais novos eram submetidos como um tipo de quarentena e que foi um meio de disciplina notável.

Essa relação entre as gerações de crianças relativamente mais velhas com as relativamente mais novas é uma questão fundamental, mas igualmente fundamental é também saber como se agrupam as idades. Assim como não é menos essencial saber como se diferenciam os sexos.

O meio infantil é sempre, sobretudo quando é livre, e não o fruto de uma educação, mas sim de uma educação das crianças pelas próprias crianças, uma forma de compreender esses fenômenos muito vastos das gerações.

Do mesmo modo, essas relações entre as geraçôes de crianças e as gerações de adultos que é a educação encontram, precisamente aqui, suas principais raízes, seu tronco, seu caule e o desenvolvimento de sua folhagem.

Nosso colega, Senhor Lahy, sabe o interesse que ele e eu sempre tivemos pelas sociedades dos homens, por toda a parte, e pela educação dos jovens dessas sociedades.

3. Em francês, argot. (N.T.)

4. É um neologismo criado pelo autor a partir de um prato típico francês que consiste em um caldo à base de carne e legumes, cozido em fogo baixo por muito tempo (N.T.). 
Mas não há apenas esse lado pelo qual a sociologia da infância pode servir ao campo da sociologia simplesmente, e também à teoria geral da educação e, mesmo, da promoção dos valores físicos da criança e, mais tarde, do homem.

Uma questão que me é familiar e que eu pude, infelizmente, apenas indicar parcialmente em uma conferência na Sociedade de Psicologia, sobre as técnicas do corpo ${ }^{5}$, permite-me entrever uma parte dos movimentos do corpo humano - não somente nos jogos, nas atitudes, no nado, na dança, etc., mas também, naturalmente, em todas as técnicas, como por exemplo, na maneira de arrancar um peso ou carregar uma carga - como o efeito do ensinamento humano, da invenção humana e da sua propagação social pela via tradicional ou pelo empréstimo.

Ideias desse tipo podem ser difundidas perfeitamente nos meios de educação física.

Por um lado, será preciso conhecer, desse ponto de vista, todas essas técnicas em seu todo [um branco na página], pois elas podem ter utilidades inimagináveis com as quais nossas ignorâncias tradicionais na Europa, por exemplo, poderiam ser totalmente informadas. Exemplo: a geração atual é, como eu tenho o costume de dizer, sem chapéu. A minha é ainda com chapéu. Aí estão questôes da sociologia da juventude e questôes da sociologia da velhice. Eu acredito que, precisamente, é útil, sob todos os pontos de vista, tratá-la em conjunto e separadamente. Da mesma forma, existem velhos senhores de barba, e isso supõe um comportamento muito diferente do de um jovem homem sem barba.

De todos os pontos de vista, o estudo da criança e do jovem como meio social é um estudo tão importante quanto o estudo dos moralistas ou dos historiadores ou das literaturas, os quais servem, mesmo assim, para a educação ensinar a moral e os usos que se quer que a criança adquira, mas por vias indiretas da arte e da autoridade. Embora, ao contrário, quando lhe ensinamos a guardar, a todo custo, a atitude que tinha quando era pequena, quando sabia se agachar e permanecer sobre seus calcanhares, tenhamos feito um bem para sua vida.

Nas duas primeiras questōes que coloquei, vemos como a sociologia da infância pode servir a todas as partes da sociologia e à própria sociologia geral. E, por outro lado, na terceira questão, na das técnicas do corpo, vemos como a sociologia em geral serve e deve servir à educação da infância.

5. Conferência proferida na Sociedade de Psicologia, em 17 de maio de 1934, e que seria publicada no Journal de Psychologie Normale et Pathologique, em 1935, tomo XXXII, n. 3-4, retomada em MAUSS, Marcel. Sociologie et anthropologie. Paris: PUF, 1950. p. 362-386. 